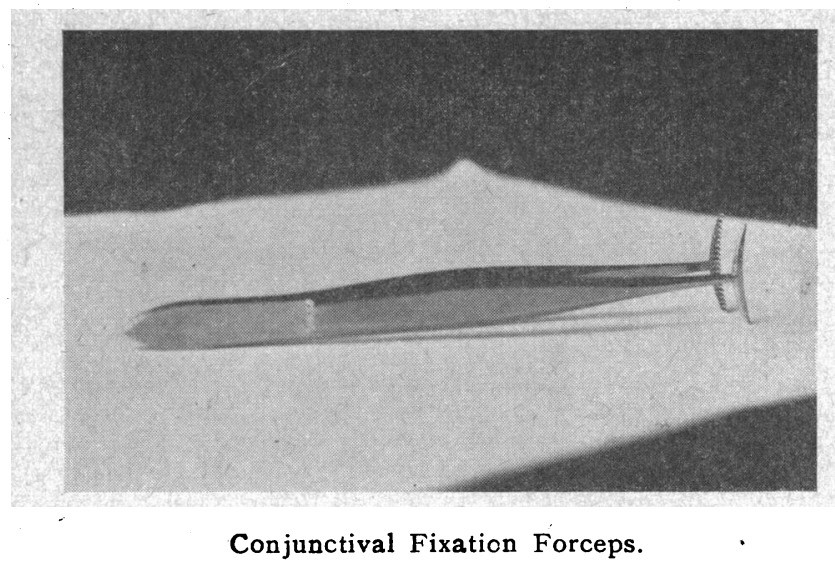

and the breadth of grip helps to prevent rotation of the eyeball in a Graefe section if the knife is not quite perfect.

It is suggested that, where cataract has developed in cases of sympathetic ophthalmia, fairly early operation might be undertaken when the slit-lamp does not show undue inflammation and the acute recurrences have subsided, despite the presence of keratic precipitates and a slight flare. The irido-capsular membrane may be softer and an opening made more easily to lift out the lens. The same would seem to apply to the after-cataract.

\title{
REFERENCES
}

FrANCESCHETTI, A. (1948).-Ann. d'Ocul., 181, 530.

FisHER, J. H. (1933). - Brit. Jl. Ophthal., 17, 35.

\section{SIMPLE CAMERA SUPPORT FOR THE OPERATING THEATRE}

BY

Gy. P. Halberg, M.D.

ARGENTINA

THE usual photographic tripods are often inconvenient and cumbersome when used in the theatre for the photography of eye operations. For this reason a simple unipod support has recently been designed. A short illustrated specification is given below.

The unipod consists of a vertical iron rod, and a horizontal flat iron tongue, supported at $90^{\circ}$ by a simple diagonal bar. The vertical member is $\frac{1}{2}$ in. solid rod, 36 in. in length. The horizontal portion is flat; $24 \mathrm{in}$. long, $1 \frac{1}{4}$ in. wide and $\frac{1}{4}$ in. thick. Two slots 
Simple Camera Support for the Operating Theatre 781

10 in. $\times \frac{1}{4}$ in. are made in its long axis to facilitate the adjustable fixing of a ball and socket camera support (Fig. 1).

The whole assembly is fixed to the operating table as shewn in Fig. 2.

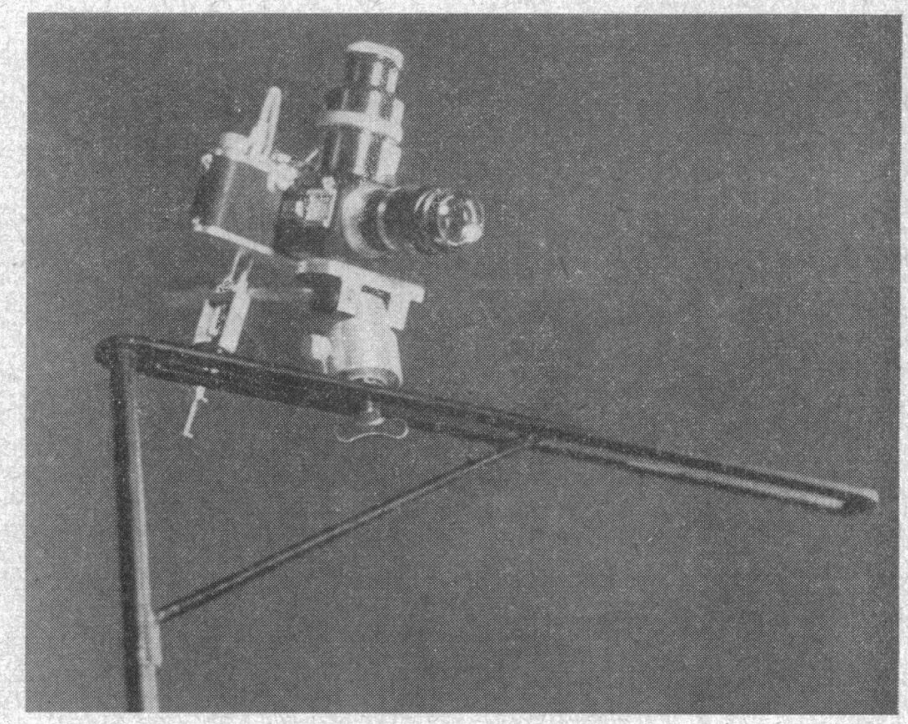

FIG. 1.

Unipod camera support, with camera and "ball and socket joint."

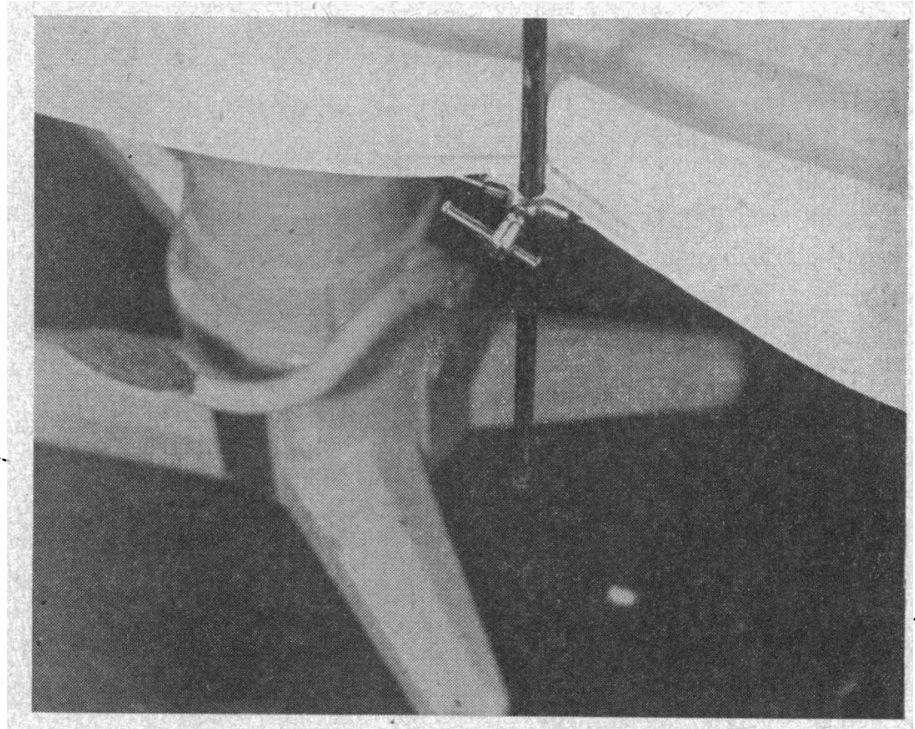

Fig. 2.

:Picture shows how unipod support is fixed to the operating table. 